\title{
Analyse of Polypharmacy and its Consequences on Nutritional Status in Elderly People Living in Nursing Home in Auvergne
}

\author{
DERLANGE Marie-Laure ${ }^{1 *}$, LESOURD Bruno ${ }^{2}$, BOYER Anne $^{3}$ and MULLIEZ Aurélien ${ }^{4}$ \\ ${ }^{1}$ Pôle Gériatrique, Centre Hospitalier de Thiers, Thiers, France \\ ${ }^{2}$ Pôle Gériatrique, CHU Clermont-Ferrand, Université de Clermont-Ferrand, Clermont-Ferrand, France \\ ${ }^{3}$ Service de Pharmacie Centre Hospitalier Universitaire, Clermont-Ferrand, France \\ ${ }^{4}$ Delegation à la recherche clinique et aux innovations (DRCI), CHU de Clermont-Ferrand, Clermont-Ferrand, France
}

Received: March 22, 2018; Accepted: April 11, 2018; Published: April 20, 2018

*Corresponding author: Pôle Gériatrique, Centre Hospitalier de Thiers, Thiers, France, E-mail: marielaure.ollier@gmail.com

\begin{abstract}
Purpose: Malnutrition and polypharmacy are two public health problems due to their high prevalence in the elderly and their serious consequences, including reduced functional ability, hospitalization and mortality.

Methods: Our study concerns 4,363 residents in 104 nursing homes in Auvergne (based on the sample of the RIDE study). The number of drugs is collected by a pharmacist from the resident's file. The polypharmacy threshold is arbitrarily set at 5 drugs or more. A Mini Nutritional Assessment (MNA) is performed for each resident and the malnutrition threshold is 17.
\end{abstract}

Results: Our population is aged on average $86.4 \pm 7.9$ years. There is $27 \%$ of undernourished and $71.65 \%$ at risk for malnutrition. The mean number of drug is at $8.3 \pm 3.6$ with $79.9 \%$ of polymedicated. We found no relationship between malnutrition and polypharmacy. Polypharmacy is inversely proportional to the functional dependency measured by the French GIR index. Age and functional dependency are two risk factors for malnutrition.

Conclusion: Chronic diseases cause dependence and anorexia, sources of malnutrition. The appropriate treatment of these chronic diseases would make it possible to fight against the weakening of functional capacity. The polypharmacy, if appropriate, does not result in malnutrition. The management of malnutrition must add at the same time nutritional cares including human aids, and tailored drug treatment of the chronic diseases.

Keywords: Malnutrition; Polypharmacy; Elderly; Physical dependency; Nursing home; Inappropriate medication;

Key Points: Very old age and reduced functional capacity are two risk factors of malnutrition in nursing home residents.

-There is no relationship between polypharmacy and malnutrition in nursing home residents.

- The management of the malnutrition with only nutritional measures is not optimum.

- Appropriate drug management of chronic diseases may reduce under nutrition.

-There is a lot of inappropriate polypharmacy with an unfavorable benefit-risk ratio or a doubtful effectiveness to a therapeutic alternative.

\section{Introduction}

Malnutrition is common among the elderly. According to the High Health Authority (HAS) and depending on the different surveys, its prevalence varies in patients living at home from $2-3 \%$ to $13,1 \%$, if adding lower ability it can raise to $30 \%$ [1-4].

By patient living in nursing home, this prevalence is more important with rates from $15 \%$ to $38.6 \%[5,6]$. This is explained by more reduced functional ability of these patients, often polypathological and older than living home patients [7].

Malnutrition is a public health problem causing many complications: nosocomial infections, pressure ulcers, falls and fractures, occurrence and aggravation of functional dependency which includes dependency on care-givers for tasks of daily life and / or dependency on physical aids, increase in hospital length of stay and increase mortality [8-13]. That causing an increase of health care expenditure [14].

Malnutrition can be avoided through screening elderly people if it is follow-up by an efficient management of risk factors. To this aim, the awareness rising among the different actors of the health system is necessary considering that many helps are now available [1,15]. The main risk factors of this malnutrition are now well-known and have been listed by the HAS [1]. 
At home, it rises with age but also and mainly with functional dependency leading to many difficulties in the supply chain, cooking and meal intakes [16-17]. Social isolation is an additional risk factor, especially in case of physical or psychological dependency [18]. Physical factors can exacerbate the risk linked to these psycho-social factors: oral health and dental problems causing masticatory disorder or oropharyngeal dysphagia [1920]. They can come from bad dental care, oral dryness, oral candidosis, otolaryngologic diseases or neurological disorders (after effects of a cerebrovascular accident, a Parkinson's disease...). Any diet when strictly followed may lead to anorexia and then malnutrition [21].

All chronic diseases are providers of malnutrition by the hypercatabolism they produce [22]. In chronic diseases, certain are predominant in the occurrence of malnutrition. This is the case of depression, cause of social isolation, anorexia but also of appetite disorders and somnolence due to psychotropic drugs [23-24] Similarly, dementia may lead to decrease of the brings (reduced functional ability, forget and incapacity to prepare meals, eating disorders) [25]. Anti-dementia drugs (cholinesterase inhibitors) can themselves lead to eating disorders and to malnutrition [26]. In addition to already mentioned treatments, diuretics, leading to xerostomia, and oral antidiabetic drugs causing digestive disorders may be responsible of malnutrition [24].

Polypharmacy alone was described as a risk factor of malnutrition [27-28]. The World Health Organization (WHO) defines polypharmacy as the administration of many drugs in the same time or administration of excessive numbers of drugs [29]. Polypharmacy ( 5 drugs or more) is found that nearly half (14 at $49 \%$ ) of oldest 75 years [30].

Polypharmacy has a high prevalence of the elderly, often with multiple illnesses and with chronic diseases. It's a current preoccupation for the public health : in fact, increasing life expectancy, continuous for more than a century, leads to a high rate of elderly, therefore to an increase of age-related chronic diseases, and then to an increase of number of drug prescriptions, especially psychotropic medication, preventive treatment of heart diseases and antihypertensive drugs. In 15 years, the prevalence of people older than 70 years taking 5 drugs a day increased from $9.7 \%$ to $20.8 \%$ and for these taking 10 drugs and more, the rate increased from $1.9 \%$ to $5.8 \%$ [31].

Is polypharmacy is confirmed in specific case, it can be inappropriate especially when the expected benefits is not realized (32) or when not following the recommendations [32]. As is the case with the antihypertensive drugs, antiarrhythmic drugs, psychotropic medications and proton pump inhibitors. It provokes an increase of drugs interactions and can cause mistakes linked of compliance with prescriptions [31-33]. It promotes adverse drug events which involves by the treatment of these adverse drug effects, an increase of polypharmacy [34].

This polypharmacy is responsible for an increase of hospitalizations, especially by an increase of falls, and is combined to an increase of death [35-36]. Finally, polypharmacy can cause problem complying when the dosing and timing of drug administration is too complicated [33].

Polypharmacy is considered a public health issue because all their complications can be avoided thanks to a high supervision of prescriptions and a reflection on the interest of the continuation of treatment. Several helps exists to educate physicians [32]

In this work, we decided to pay our attention on the link between polypharmacy and nutritional status.

\section{Methods}

The main aim of this study is to analyze the relation between polypharmacy and nutritional status on the largest population those published. We also looked for additional risk factors of the malnutrition such as age or functional dependency.

\section{Patients in RIDE Study}

Our study is based on the data of the RIDE study leads by ARS (AgenceRégionale de Santé) Auvergne. This study was concerned on two pathologies: iatrogenesis and malnutrition in nursing home in Auvergne. This study, named RIDE (Risquelatrogénie - Dénutritiondans les EHPAD) is aimed to help the EHPAD (Etablissementd'Hébergement pour PersonnesAgéesDépendantes or nursing homes) to improve their care for those two pathologies, considering the important impacts on the public health because these factors are increasing morbi-mortality and are avoidable.

The study concerned 136 EHPAD of the Auvergne area and involved 6613 elderly people, $60 \%$ of the targeted population. In the fact, a team constituted of a pharmacist and a dietitian visited each EHPAD to collect the necessary data relative to the study (a specific language has been established to respect the anonymous character of the resident, the concerned establishment and the prescriber; the study was registered to the French CNIL) [37].

The collected data were:

- The running of the institution (status, capacity, staff and participant coming in the establishment, followed trainings, presence of an intern pharmacy, therapeutic guide, organization in the kitchen and meals.)

- Characteristics of residents (sex, date of birth and arrival in the EHPAD, GIR [38], GMP [39], where they come from, social environment, reason of arrival, medical follow-up)

- Malnutrition characteristic (use of different tools of diagnostic recommended by HAS (Body Mass Index (BMI), weight variation, blood test (Albumin, CRP), Mini Nutritional Assessment (MNA) [40]

- Modality of the nutritional care (texture-modified meals, enriched food, additional snacks, dietary supplement, artificial nutrition), presence of restricted diet, oral and dental disorders...

- Regarding the malnutrition, the dietitian dedicated to the study realized a MNA and calculated the BMI (she had to weight and measure the size of the concerned person and when it was no possible, she measured the knee-heel length) for each studied resident in the way to evaluate the nutritional status. 
- Regarding the medical treatment, all have been totally collected for each concerned resident in the way to determine the number of different drugs prescribed. A pharmacological analysis has been realized at the university hospital pharmacy of Clermont-Ferrand, after anonymization of prescriptions, to determine the presence of potential inappropriate treatment, grouped in two categories: the unfavorable risk-benefit or doubtful efficiency. All drugs interactions have been listed. This work has been done thanks the Pharmatest ${ }^{\circledR}$ software.

\section{Polypharmacy threshold}

For our study, we considered this threshold as being 5 drugs (the most frequently used in the studies). This choice is based on the logic of linear relationship between the risk of adverse effects and the number of drugs [30]. Excessive polypharmacy threshold is arbitrarily determined at more than 10 drugs [30].

\section{Nutritional status}

Nutritional status is determined only by the MNA because the BMI can't serve to identify at the same time the malnourished and obese people and that the albumin is under dosed (3\% in RIDE study). Considering this nutritional status given by MNA, we can classify the patients in three groups. When the MNA rate is under 17 , we consider the patient as malnourished, when the rate is between 17 and 23 he is at risk for malnutrition and when the rate is same or over 24 , the patient is well-nourished.

\section{Statistical analysis}

All analyses were performed using Stata software (version 12, StataCorp, College Station, TX). All tests were two-sided and a p-value $<5 \%$ was considered statistically significant. Study population is described by frequencies and associated percentages for categorical data and by mean ?standarddeviation and range [min-max] for continuous data. Comparison between groups (polypharmacy and MNA classes) were carried out using Chisquared test for categorical data (or Fisher's exact test when appropriate) and using analysis of variance (ANOVA) for continuous data (or with the Kruskall-Wallis when data distribution was not normal, normality assessed using distribution plots and Shapiro-Wilk's test). Post-hoc tests were used when significance was reach (using Marascuilo procedure or Dunn's test according to data type).

\section{Results}

In our study, we included all people whose their MNA were calculated.

The study evaluates 4363 patients spread into 104 EHPAD (figure 1).

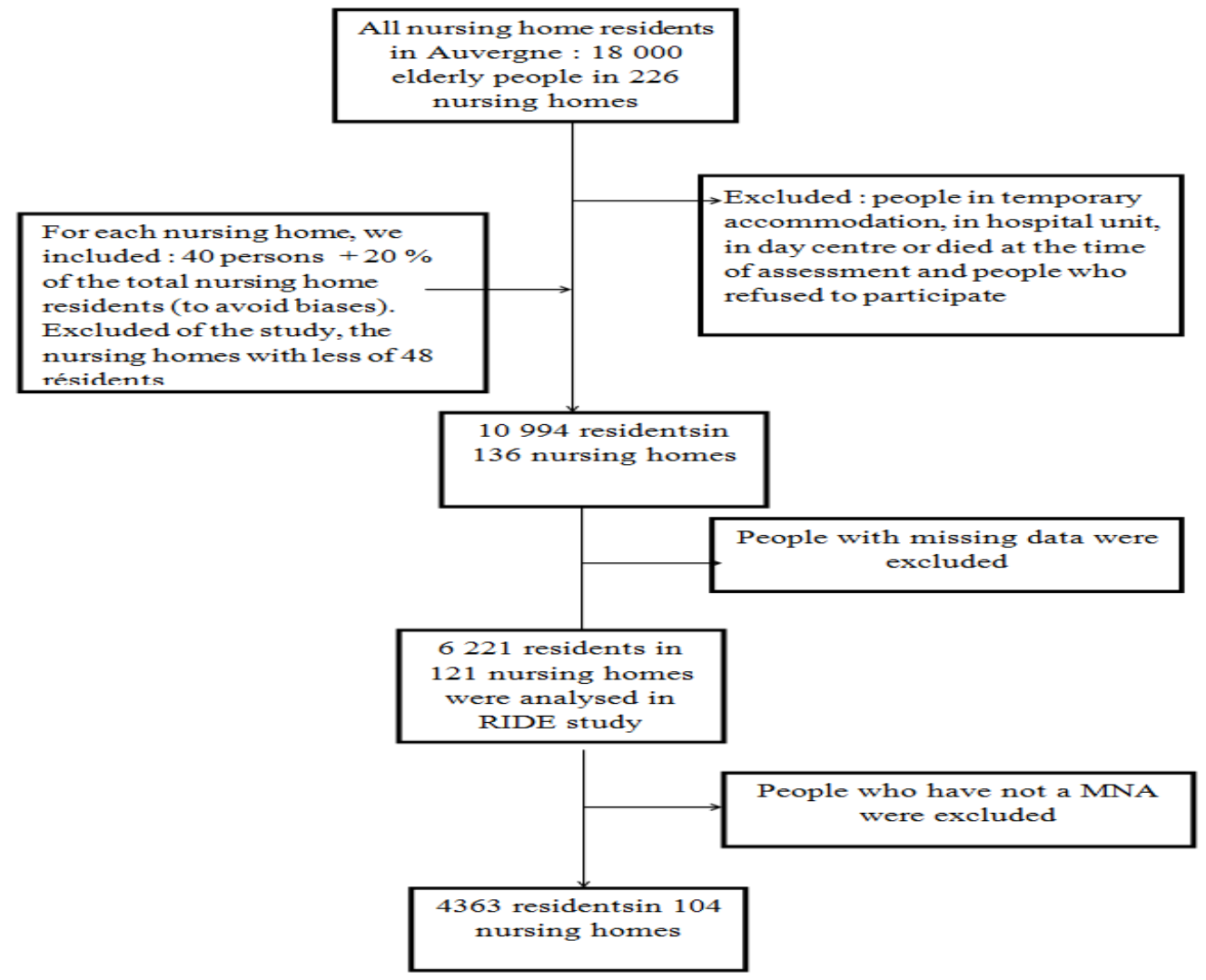

Figure 1: Flow diagram of included patient 
Table 1: Characteristics of included residents, with comparison between the regional study, RIDE [37], and the national studies [1,30,42]

\begin{tabular}{|c|c|c|c|c|}
\hline \multirow[b]{2}{*}{ Average number of drugs } & \multicolumn{2}{|c|}{ Our study } & \multirow{2}{*}{$\begin{array}{c}\text { RIDE study (37) } \\
8+/-4\end{array}$} & \multirow[t]{2}{*}{ National studies } \\
\hline & $8.28+/-3.63$ & Between 0 and 27 & & \\
\hline$-<5$ drugs & $14.94 \%$ & $\mathrm{~N}=652$ & $23 \%$ & \multirow{4}{*}{14 à $49 \%$ (30) } \\
\hline - between 5 and 9 & $49.99 \%$ & $\mathrm{~N}=2181$ & $50 \%$ & \\
\hline - between 10 and 14 & $29.91 \%$ & $\mathrm{~N}=1305$ & $23 \%$ & \\
\hline$->15$ & $5.16 \%$ & $\mathrm{~N}=225$ & $3 \%$ & \\
\hline $\begin{array}{l}\text { Average age } \\
\text { In years }\end{array}$ & $86.38+/-7.92$ & $(40.2-113.2)$ & $86+/-8,5$ & \\
\hline$-<65$ years & $2.06 \%$ & $\mathrm{~N}=90$ & & \\
\hline - Between 65 and 80 years & $14.72 \%$ & $N=642$ & & \\
\hline - Between 80 and 90 years & $49.11 \%$ & $\mathrm{~N}=2141$ & & \\
\hline - > 90 years & $34.11 \%$ & $\mathrm{~N}=1487$ & & \\
\hline Average GIR /6 & $2.90+/-1.42$ & $(1-6)$ & & \\
\hline GIR $1-2$ & $47,82 \%$ & $\mathrm{~N}=2037$ & $47 \%$ & $48 \%(42)$ \\
\hline - GIR 1 & $16.50 \%$ & $\mathrm{~N}=703$ & & \\
\hline - GIR 2 & $31.31 \%$ & $\mathrm{~N}=1334$ & & \\
\hline GIR 3-4 & $38.85 \%$ & $N=1655$ & $36 \%$ & \\
\hline - GIR 3 & $17.23 \%$ & $\mathrm{~N}=734$ & & $16 \%(42)$ \\
\hline - GIR 4 & $21.62 \%$ & $\mathrm{~N}=921$ & & $20 \%(42)$ \\
\hline GIR 5-6 & $13,33 \%$ & $N=568$ & $12 \%$ & \\
\hline - GIR 5 & $7.16 \%$ & $\mathrm{~N}=305$ & & $8 \%(42)$ \\
\hline - GIR 6 & $6.17 \%$ & $N=263$ & & $8 \%(42)$ \\
\hline Average MNA /30 & $18.48+/-3.04$ & $(4.5-26)$ & & \\
\hline$-<17$ & $27 \%$ & $\mathrm{~N}=1178$ & $24 \%^{\dagger}$ & 15 à $38.6 \%$ (1) \\
\hline - Between 17 and 23.5 & $71.65 \%$ & $N=3126$ & & \\
\hline$->23.5$ & $1.35 \%$ & $\mathrm{~N}=59$ & & \\
\hline
\end{tabular}

The included persons (table 1), representative of nursing home residents in Auvergne, have on average of 86.4 ? 7.9 years (40.2-113.2). The over 80 years old are the most represented (83.2\%). The average GIR (figure 2) is 2.9 ? 1.4 whose most of them are partially or totally dependent $(47.82 \%$ for GIR $1-2$, $38.8 \%$ for GIR 3-4) and very a few are autonomous (13.3\% GIR 5-6). The average MNA (figure 3) is 18.47 ? 3.04 (4.5-26); nearly three quarters of the included population is at risk of malnutrition $(71.65 \%)$ and a very few people are well-nourished (1.35\%).

The population included takes an average of 8.3 ? 3.6 drugs (0-27). The polypharmacy is most common: $85.1 \%$ of the residents. A large majority (58.7\% of polymedicated people, so $46 \%$ of the residents) has a moderated polypharmacy and takes between 5 and 9 drugs. Otherpolymedicated people, $41.2 \%$ (35.1\% of residents), got an important polypharmacy with more than 10 drugs.

Polypharmacy (table 2) is not linked to the age however

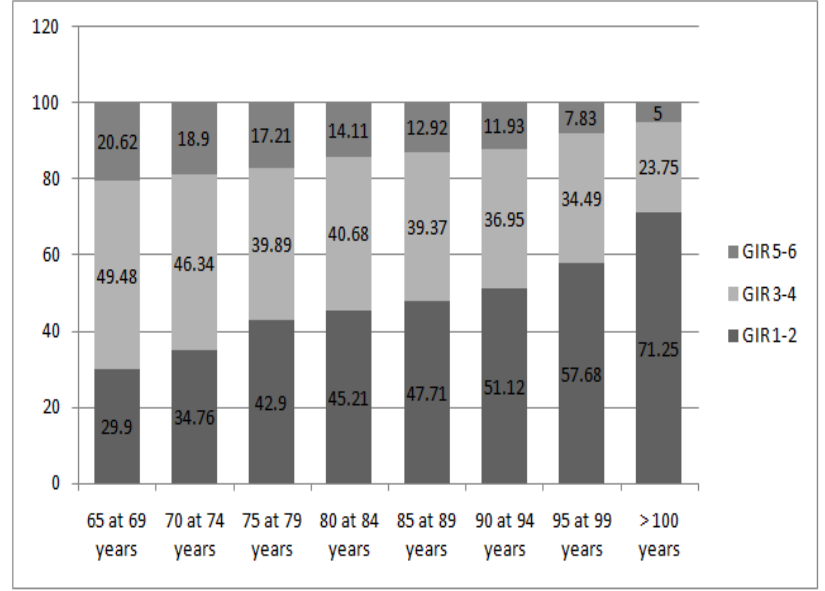

Figure 2: Dependency (\% of GIR classes based on age) 


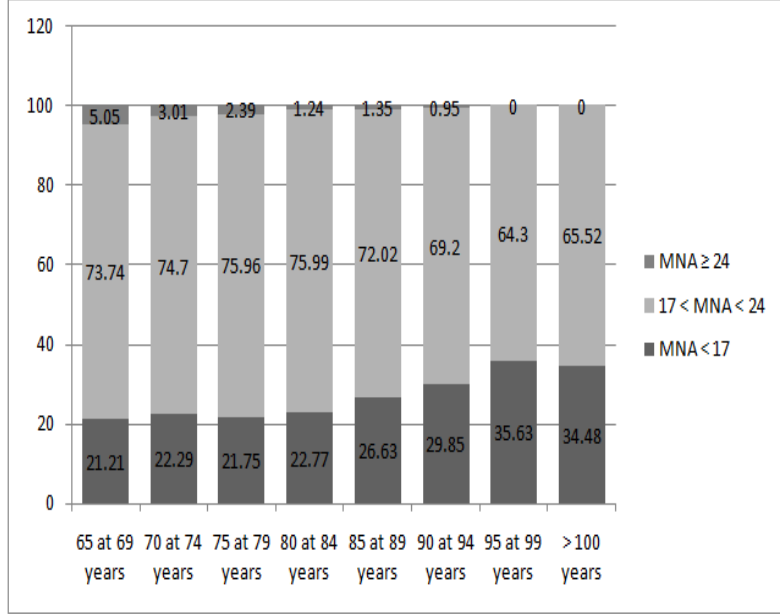

Figure 3: Nutritional status ( $\%$ of MNA classes based on age) we can see for the very old (more than 95 years) less drugs. Nevertheless, there is a significant link between polypharmacy and GIR, an increase of functional dependency induces a decrease of number of drugs.

The high age and the reduced functional capacity are the risk factors of malnutrition (table 3), these two parameters being linked. In fact, there is a relationship with GIR and age, the older the patient is, the more dependent he is $(\mathrm{p}<0.001)$. However, we don't find any link between the number of drugs and the nutritional status.

\section{Discussion}

Our population is representative of nursing home residents speaking in term of nutritional status and dependency with a similar distribution to the national average from the INSEE (table 1) $[1,41,42]$. Our population is more exposed to the malnutrition risk and only few residents had a normal nutritional status. Our population also takes more drugs (figure 4) $[30,43]$. This can be

\begin{tabular}{|c|c|c|c|c|c|}
\hline \multirow{2}{*}{ Table 2: Relationship between number of drugs and age, dependency and nutritional status } & \multicolumn{3}{|c|}{ Polypharmacy } & p-value \\
\hline & $<\mathbf{5 ~ d r u g s}$ & $\begin{array}{c}\text { Between } \mathbf{5} \text { and } \mathbf{9} \\
\text { drugs }\end{array}$ & $\begin{array}{c}\text { Between 10 and 14 } \\
\text { drugs }\end{array}$ & $>\mathbf{1 5}$ drugs & $\mathrm{p}=0.076$ \\
\hline $\begin{array}{c}\text { Age } \\
\text { In years }\end{array}$ & $86.94+/-8.26$ & $86.48+/-7.95$ & $85.99+/-7.8$ & $86.21+/-7.29$ & $\mathrm{p}<0.001$ \\
\hline GIR /6 & $2.72+/-1.52$ & $2.85+/-1.42$ & $3.01+/-1.37$ & $3.25+/-1.31$ & $\mathrm{p}=0.0097$ \\
\hline MNA /30 & $18.47+/-3.17$ & $18.33+/-3.1$ & $18.68+/-2.91$ & $18.67+/-2.78$ & \\
\hline
\end{tabular}

Table 3: Relationship between age and number of drugs

\begin{tabular}{|c|c|c|c|c|c|c|c|c|c|}
\hline $\begin{array}{c}\text { Age } \\
\text { In years }\end{array}$ & $<65$ & 65 à 69 & 70 à 74 & 75 à 79 & 80 à 84 & 85 à 89 & 90 à 94 & 95 à 99 & $>100$ \\
\hline Number of drugs & $8.13+/-3.77$ & $\begin{array}{c}8.3+/- \\
3.78\end{array}$ & $\begin{array}{c}8.23+/- \\
3.6\end{array}$ & $\begin{array}{c}8.63+/- \\
3.77\end{array}$ & $\begin{array}{c}8.57+/- \\
3.66\end{array}$ & $\begin{array}{c}8.32+/- \\
3.54\end{array}$ & $\begin{array}{c}8.07+/- \\
3.59\end{array}$ & $\begin{array}{c}7.98+/- \\
3.72\end{array}$ & $\begin{array}{c}7.52+/- \\
3.89\end{array}$ \\
\hline
\end{tabular}

Table 4: Relationship between nutritional status and age, dependency and number of drugs

\begin{tabular}{|c|c|c|c|c|}
\hline & MNA $>\mathbf{2 3 . 5}$ & $\mathbf{2 3 , 5}>$ MNA $\geq \mathbf{1 7}$ & MNA $<\mathbf{1 7}$ & p-value \\
\hline Age In years & $82.52+/-8.07$ & $86.08+/-7.89$ & $87.99+/-7.88$ & $\mathrm{p}<0.001$ \\
\hline GIR /6 & $3.95+/-0.99$ & $3.02+/-1.41$ & $2.52+/-1.40$ & $\mathrm{p}<0.001$ \\
\hline Number of drugs & $8.24+/-0.39$ & $8.33+-3.63$ & $8.16+/-3.61$ & $\mathrm{p}=0.36$ \\
\hline
\end{tabular}

explained by our older population because our study is more recent [41]. In fact, the DRESS (Direction de la Recherché, des Etudes, de l'Evaluation et des Statistiques) compared the nursing home population between 2007 and 2011 and the population became increasingly aged (average in age and in date of arrival) and increasingly dependent [42].

To study the polypharmacy, it is interesting to focus on nursing home population, because she is polypathological, older than people living at home and she has no self-medication.

Only few studies compared the link between the nutritional status and the polypharmacy with such large population sample. Many studies used the same criteria to determine the nutritional status (MNA) and the polypharmacy ( $>5$ and $>10$ drugs).

Verbrugghe studied 1188 belgian nursing home residents in 2004, then in 2007 with a similar repartition with our study about the nutritional status (19.4\% malnourished vs $27 \%)$, age (84.3 vs 86.4 years old) and reduced functional capacity $(57.4 \%$ totally dependent vs $47.8 \%$ ). Just like us, he is not finding a link between the number of drugs and the nutritional status [44].

Suominen explored 2114 nursing home residents in 
Helsinki. Their population is similar to ours for the nutritional classifications (MNA < 24 for $89 \%$ vs $98.6 \%$ ), the average age ( 83.3 vs 86.4 years old) and the average number of drugs ( 8.1 vs 8.3) [45]. This study does not find a significant relationship between the nutritional status and the number of drugs.

However, another studies found a link between polypharmacy and malnutrition.

Jyrkkä studied, two times, 294 elderly people living at home. His population is lightly younger ( 81.3 then 84 vs 86.4 years old), less dependent $(61.2 \%$ then $46.9 \%$ of autonomous people vs $13.3 \%$ ) but suffering more from malnutrition (average MNA at 12.8 then 12.1 vs 18.5) [27]. The study found a significant drop of the MNA rate in polymedicated people but all other groups were malnourished (MNA at 13.1 in non-polypharmacy group and 12.1 in excessive polypharmacy group).

Griep studies the number of drugs depending on the MNA nutritional statuson 81 elderly people living in nursing homes. Its population is lightly younger than ours (83.4 vs 86.4 yearsold), less dependent (29.6\% totally or partially dependent vs $86.7 \%)$, less malnourished (> 50\% well-nourished vs $1.35 \%$ and $2 \%$ malnourished vs 27\%) and taking less drugs (average number of drugs at 5.5 vs 8.3) [46]. He finds a malnutrition risk factor with the polypharmacy but knowing that people with malnutrition are significantly younger and the sample is small.

Visvanathan studied 250 elderly people living at home and found a significant link between malnutrition and polypharmacy but with a low odd ration low at 1.08 [28]. In this case, its population is younger than in our study (79 vs 86.4 years old), taking less drugs (average number of drugs at $4.9 \mathrm{vs} 8.3$ ) and had a better nutritional status (MNA $<24$ at $43.2 \%$ vs $98.6 \%$ ).

We can note that in all the studies showing a link between polypharmacy and malnutrition, there are similar points: a younger population, less dependent and less malnourished. By the way, their populations live mainly at home and their samples are small. Considering all that points, we can say that the studies are not comparable.

If our population is mainly suffering from malnutrition it's because the population is older and more dependent than people living at home. Furthermore, the malnutrition is systematically (so more) detected in nursing home rather than at home. Indeed, a monthly weighing is done on majority of residents $168 \%$ in RIDE study) which is not the case in the liberal practical at home. According to the RIDE study, the management of malnutrition is very often realized ( $72 \%$ of nursing home) using texturemodified meals $(40 \%)$, dietary supplement $(18 \%)$, enriched foods $(11 \%)$, additional snacks $(0.5 \%)$, enteral nutrition $(0.2 \%)$ and often a help for the taking of the meals [37]. At sight of the high rate of persistent malnutrition after 2 years in nursing home (61\% of malnourished), we can think that the management of the malnutrition on only nutritional aspect is not optimum. There are a number of possible explanations: a caloric quantity being not enough in the texture-modified meals, a management of dental state not enough systematical and mainly an insufficient time for the meals [37].
However, we can also think that certain risk factors of malnutrition are more important than other and will require a specific management in addition to nutritional management. For example, a high dependency and chronic diseases, which cause anorexia. Treating these disorders with sometimes lot of drugs could lead to the abolition of this risk factor and could help to a good nutritional status. Unfortunately, on our population, the polypharmacy is not necessarily appropriated. In fact, in the RIDE study, extract from our population, up to $67 \%$ of the patients had an inappropriate polypharmacy, that means with an unfavorable benefit-risk ratio or a doubtful effectiveness to a therapeutic alternative [37].

The idea which is now developing is an appropriate or inappropriate medication. Indeed, several studies refer to the underuse of medications.

We may therefore consider that have the adequate treatment is less deleterious than the disease itself on the nutritional status.

Nowadays we easily talk about underuse of medications (preventive drug in particular) than polypharmacy, especially with the increase of life expectancy [43]. This shows than the chronic diseases are more detrimental than the drug itself on mortality but probably also on malnutrition.

The underuse of drug is especially frequent in the cardiovascular diseases (high blood pressure, heart failure, coronary artery disease, atrial fibrillation) but also in osteoporosis and depression, leading to functional dependency and malnutrition [43].

For the moment, no study shows the link between the appropriate medication and the improvement of the nutritional status. However a Canadian study showed the decrease in the number of drugs (following a health policy) finalized with a stop of certain essential drugs causing a worsening of the state of health (increasing in decompensation and consultations in emergency) [47].

\section{Conclusions}

Malnutrition is a frequently disorder in the very old nursing home population. It has seriously consequences on hospitalization and on functional capacity, causing themselves malnutrition. Its screening in nursing homes is very frequent, showing a good awareness about this pathology and its consequences. However, the nutritional management is not always optimal with difficulties in implementing (enough assistance, staff time and length of meals, rare enteral nutrition...).

The chronic diseases are also a well-known risk factor for malnutrition. The appropriate treatment, causing an increase in number of drugs, often resulting in polypharmacy, but it can lead to improvement in health and in nutritional status for patients. With ageing of the population the chronic diseases increase. However, the past studies showed, on people living at home, a detriment effect of polypharmacy (poor compliance, drugs interactions...). And a lot of drugs were stopped on older ages. This deleterious effect is not found in nursing home. 
Recent studies show that the drug management of chronic diseases, causing mostly a polypharmacy, is less deleterious than the polypharmacy itself, with a health improvement. Now, we talk about underuse of drugs, causing serious diseases (cardiac diseases for example) and chronic diseases decompensations. All these consequences cause dependency and malnutrition.

Now, the malnutrition management has to be at the same time nutritional, human with assistance on the dependent persons, but also with drugs for the treatment of chronic diseases.

Even though our results showed no correlation between polypharmacy and malnutrition, such relation may exist for different elderly populations. Indeed relationships between those two factors have been shown for elderly living in their homes or living in nursing home in the younger people $[27,28,46]$.

Perhaps such relationship may be observed only in less dependent elderly, or only in some subpopulations living in nursing homes. Deeper research, including in our population is needed to precise which elderly subpopulations maybe concerned.

\section{Acknowledgements}

Thanks for Auvergne ARS to provide RIDE data. We are grateful to Martial DANGIN for his help in this manuscript.

\section{References}

1. Clinical practice guidelines from the French Health High Authority: nutritional support strategy in protein-energy malnutrition in the elderly. 2007.

2. De Groot CPGM, Van Staveren WA. Undernutrition in the European SENECA studies. Clin Geriatr Med. 2002;18(4):699-708. doi: 10.1016/s0749-0690(02)00043-5

3. Wallace JI, Schwartz RS, LaCroix AZ, Uhlmann RF, Pearlman RA. Involuntary weight loss in older outpatients: incidence and clinical significance. J Am Geriatr Soc. 1995;43(4):329-337. doi: 10.1111/ j.1532-5415.1995.tb05803.x

4. Ödlund Olin A, Koochek A, Ljungqvist 0, Cederholm T. Nutritional status, well-being and functional ability in frail elderly service flat residents. Eur J Clin Nutr. 2005;59(2):263-270. doi: 10.1038/ sj.ejcn.1602067

5. Gerber V, Krieg MA, Cornuz J, Guigoz Y, Burckhardt P. Nutritional status using the Mini Nutritional Assessment questionnaire and its relationship with bone quality in a population of institutionalized elderly women. J Nutr Health Aging. 2003;7(3):140-145. DOI: 10.1038/sj.ejcn.1602341

6. Crogan NL, Pasvogel A. The influence of protein-calorie malnutrition on quality of life in nursing homes.J Gerontol A Biol Sci Med Sci. 2003;58(2):159-164. doi :10.1093/gerona/58.2.M159

7. Bouvier G, Lincot L, Rebiscoul C. Living at home or in nursing home: influences of age, health and family environment - Insee References INSEE(OUV) . 2011:37-39.

8. Rodríguez-García J, Gamiño-Iriarte A, Rodea-Montero ER. Nutritional Status and Nosocomial Infections among Adult Elective Surgery Patients in a Mexican Tertiary Care Hospital. PLoS One. 2015;10(3):e0118980. doi:10.1371/journal.pone.0118980
9. Neloska L, Damevska K, Andjelka Nikolchev, Lidija Pavleska, Biljana Petreska-Zovic, Milenko Kostov. The Association between Malnutrition and Pressure Ulcers in Elderly in Long-Term Care Facility. Open Access Maced J Med Sci. 2016;4(3):423-427. doi: 10.3889/oamjms.2016.094

10. Neyens J, Halfens R, Spreeuwenberg M, Meijers J, Luiking Y, Verlaan $\mathrm{G}$, et al. Malnutrition is associated with an increased risk of falls and impaired activity in elderly patients in Dutch residential longterm care (LTC): a cross-sectional study. Arch Gerontol Geriatr. 2013;56(1):265-269. doi: 10.1016/j.archger.2012.08.005

11. Galanos AN, Pieper CF, Cornoni-Huntley JC, Bales CW, Fillenbaum GG. Nutrition and function: is there a relationship between body mass index and the functional capabilities of community-dwelling elderly?. J Am GeriatrSoc. 1994;42(4):368-373. doi: 10.1111/j.15325415.1994.tb07483.x

12. Thomas DR, Zdrowski CD, Wilson M-M, Conright KC, Lewis C, Tariq S, Morley JE. Malnutrition in subacute care. Am. J Clin Nutr. 2002;75(2):308-313.

13. Söderström L, Rosenblad A, Thors Adolfsson E, Bergkvist L. Malnutrition is associated with increased mortality in older adults regardless of the cause of death. See comment in PubMed Commons belowBr J Nutr. 2017;117(4):532-540. doi: 10.1017/ s0007114517000435

14. Marinos E. The cost of malnutrition in England and potential cost savings from nutritional interventions. Print edition. 2015

15. Diagnostic assessment of protein-energy malnutrition in hospitalized adults. Anaes/Guidelines. 2003.

16. Woo J, Ho SC, Sham A. Longitudinal changes in body mass index and body composition over 3 years and relationship to health outcomes in Hong Kong Chinese age 70 and older. J Am Geriatr Soc. 2001; 49(6):737-746. doi: 10.1046/j.1532-5415.2001.49150.x

17. Dehghankar L, Shahrokhi A, Sonia Oveisi, Neda Esmailzadehha, Azam Ghorbani. Impact of Functional Capacity on Nutritional Status of Hospitalized Elderly in Qazvin, Iran. Biotech Health Sci. 2016;3(1):e34470. doi: 10.17795/bhs-34470

18. Boulos C, Salameh P, Barberger-Gateau P. Social isolation and risk for malnutrition among older people. Geriatr Gerontol Int. 2017;17(2):286-294. doi: 10.1111/ggi.12711

19. Marcenes W, Steele JG, Sheiham A, Walls AW. The relationship between dental status, food selection, nutrient intake, nutritional status, and body mass index in older people. Cad Saude Publica. 2003;19(3):809-816. doi: 10.1590/s0102-311x2003000300013

20. Carrión S, Cabré M, Monteis R, Roca M, Palomera E, Serra-Prat $\mathrm{M}$, et al. Oropharyngeal dysphagia is a prevalent risk factor for malnutrition in a cohort of older patients admitted with an acute disease to a general hospital. Clin Nutr. 2015;34(3):436-442. doi: 10.1016/j.clnu.2014.04.014

21. Roberts SB, Fuss P, Heyman MB, Evans WJ, Tsay R, Rasmussen H, et al. Control of food intake in older men. JAMA. 1994; 272(20):16011606. doi: 10.1001/jama.272.20.1601

22. Bilbao-Garay J, Barba R, Losa-Garcia JE, Martin H, Garcia de Casasola G, Castilla V, et al. Assessing clinical probability of organic disease in patients with involuntary weight loss: a simple score. Eur J Intern Med. 2002;13(4):240-245. doi: 10.1016/s0953- 


\section{5(02)00032-8}

23. Callen BL, Wells TJ. Screening for nutritional risk in communitydwelling old-old. Public Health Nurs. 2005; 22(2):138-146. doi: 10.1111/j.0737-1209.2005.220207.x

24. Martel J, Gagnon J. Taste disturbance due to medication. Pharmactuel. 2002;35:122-127.

25. Roqué $M$, Salvà $A$, Vellas B. Malnutrition in community-dwelling adults with dementia (NutriAlz Trial). J Nutr Health Aging. 2013;17(4):295-299. doi: 10.1007/s12603-012-0401-9

26. SheffrinM, Miao Y, Boscardin WJ, Steinman MA. Weight Loss Associated with Cholinesterase Inhibitors In Patients With Dementia in a National Healthcare System. J Am Geriatr Soc. 2015;63(8): 1512-1518. doi: 10.1111/jgs.13511

27. Jyrkkä J, Enlund H, Lavikainen P, Sulkava R, Hartikainen S. Association of polypharmacy with nutritional status, functional ability and cognitive capacity over a three-year period in an elderly population. Pharmacoepidemiol Drug Saf. 2011; 20(5):514-522. doi: $10.1002 /$ pds.2116

28. Visvanathan R, Macintosh C, Callary M, Penhall R, Horowitz M, Chapman I. The nutritional status of 250 older Australian recipients of domiciliary care services and its association with outcomes at 12 months. J Am Geriatr Soc. 2003;51(7):1007-1011. doi: 10.1046/j.1365-2389.2003.51317.x

29. WHO. A glossary of terms for community health care and services for older persons. In Aging and Health Technical Report. 2004. Available from: http://www.who.int/iris/handle/10665/68896

30. Monégat M, Sermet C. Polypharmacy: definitions, assessments and issues. Investigation of IRDES. 2015.

31. Guthrie B, Makubate B, Hernandez-Santiago V, Dreischulte T. The rising tide of polypharmacy and drug-drug interactions: population database analysis 1995-2010. BMC Med. 2015;13:74. doi: 10.1186/s12916-015-0322-7

32. Gallagher P, Ryan C, Byrne S, Kennedy J, O'Mahony D. STOPP (Screening Tool of Older Person's Prescriptions) and START (Screening Tool to Alert doctors to Right Treatment). Consensus validation. Int J Clin Pharmacol Ther. 2008;46(2):72-83. doi: $10.5414 /$ cpp 46072

33. Bedell SE, Jabbour S, Goldberg R, Glaser H, Gobble S, Young-Xu $Y$, et al. Discrepancies in the use of medications: Their extent and predictors in an outpatient practice. Arch Intern Med. 2000;160(14):2129-2134. doi: 10.1001/archinte.160.14.2129

34. Field TS, Gurwitz JH, Avorn J, McCormick D, Jain S, Eckler M, et al. Risk factors for adverse drug events among nursing home residents. Arch Intern Med. 2001;161(13):1629-1634. doi: 10.1001/ archinte.161.13.1629

35. Frazier SC. Health outcomes and polypharmacy in elderly individuals: an integrated literature review. J Gerontol Nurs. 2005;31(9):4-11.

36. Neutel CI, Perry S, Maxwell C. Medication use and risk of falls. Pharmacoepidemiol Drug Saf. 2002;11(2):97-104. DOI: 10.1002/ pds.686

37. RIDE study (Iatrogenic and Nutritional risks in Nursing homes in Auvergne). Assessment of medical cares. http://www.ars. auvergne.sante.fr/Etude-RIDE.137000.199.html

38. Social Action and Family Code - Article R322-3; Annexe 2-1.

39. Social Action and Family Code - Article R314-170-1; Annexe 3-6.

40. Guigoz Y, Vellas B, Garry PJ. Assessing the nutritional status of the elderly: The Mini Nutritional Assessment as part of the geriatric evaluation. Nutr Rev. 1996;54(1 Pt 2):S59-S65. doi : 10.1111/ j.1753-4887.1996.tb03793.x

41. Ferry M, Alix E, Brocker P, Constans T, Lesourd B, Mischlich D, Pfitzenmeyer P, Vellas B. Epidemiology of malnutrition. In: Ferry M, Alix E, Brocker P, Constans T, Lesourd B, Mischlich D, Pfitzenmeyer P, Vellas B, ed. Nutrition of the elderly 3rdédition. Collection Abrégés de médecine.Issy-les-Moulineaux: Masson; 2007. p. 93102.

42. DREES study. n899. 2014. Available from: http://www.silvereco. fr/wp-content/uploads/2015/01/DREES-Résidents-dEHPADen-2011.pdf

43. Legrain S. Medication use in the elderly. HAS. 2005

44. Verbrugghe M, Beeckman D, Van Hecke A, Vanderwee K, Van Herck $\mathrm{K}$, Clays $\mathrm{E}$, et al. Malnutrition and associated factors in nursing home residents: A cross-sectional, multi-centre study. Clin Nutr. 2013 ;32(3):438-443. doi : 10.1016/j.clnu.2012.09.008

45. Suominen M, Muurinen S, Routasalo P, Soini H, Suur-Uski I, Peiponen A, et al. Malnutrition and associated factors among aged residents in all nursing homes in Helsinki. Eur J Clin Nutr. 2005;59(4):578583. doi: 10.1038/sj.ejcn.1602111

46. Griep I, Mets TF, Collys K, Ponjaert-Kristoffersen I, Massart DL. Risk of malnutrition in retirement homes elderly persons measured by the mini-nutritional assessment. J Gerontol A Biol Sci Med Sci. 2000;55(2):M57-M63. doi: 10.1093/Gerona/55.2.M57

47. Tamblyn R, Laprise R, Hanley JA, Abrahamowicz M, Scott S, Mayo $\mathrm{N}$, et al. Adverse events associated with prescription drug costsharing among poor and elderly $\mathrm{p}$ 